\title{
Developing professional identity in health professional students
}

Authors: Kathleen Leedham-Green, Alec Knight, Rick ledema

Kathleen Leedham-Green is a research fellow at the Medical Education Research Unit at Imperial College London. She teaches on the Masters in Public Health and Masters in Clinical Education at King's College London and the Masters in Surgical Education at Imperial College London. Alec Knight is a post-doctoral researcher and educator at King's College London with interests in health services research, applied psychology, medical education, public health, health policy, and implementation science. Rick ledema is professor \& director of the Centre for Team-based Practice \& Learning in Health Care at King's College London.

\section{Abstract}

Professional identity formation is a relatively new area of interest within health professional education, gaining academic attention after the Carnegie Foundation Report on Medical Education of 2010 called for its introduction into medical curricula in the United States. This chapter presents a critical discussion, introducing various schools of thought, and provides theoretically informed suggestions for practice. The authors explore both conventional identity formation and more complex modern reconfigurations of healthcare professional identity. The chapter starts with an overview of different stances on what professional identity means, drawing on a variety of literatures including sociological and organizational scholarship. Next, a range of theorie s of identity formation are presented, including socialization and transformation. A matrix model is introduced to inform curricular planning, which can be used flexibly within different institutions or contexts. The authors discuss and critique a number of focused strategies for educators including role modeling, mentoring, reflective practice, responding to the hidden curriculum, authentic role experiences and simulation-based education, communities of practice and activity theory, student engagement, and assessment practices. The chapter concludes with possible future directions in healthcare professionalidentity education. 


\section{Contents}

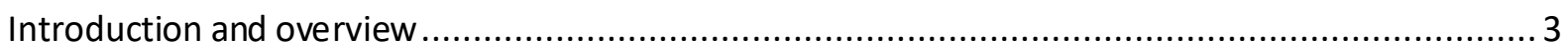

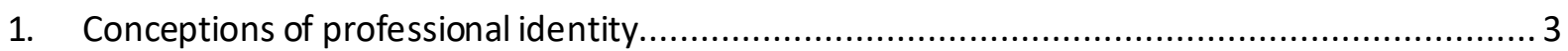

Professional identity as 'ideal': a collective contract with society ............................................ 3

Professional identity as 'self and other': tribes and siloes ....................................................... 4

Professional identity as an expression of status: hierarchies and power .............................. 4

Professional identity as a coping strategy: depersonalisation and detachment ........................... 5

Professional identity as how we are seen by others: culture and identity .............................. 5

Professional identity as contextual and situated: a sociocultural perspective.............................. 5

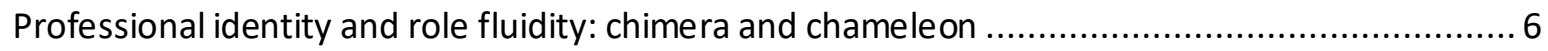

Professional identity as a transcendent attribute: fact or fiction? ............................................. 6

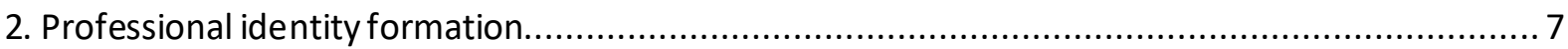

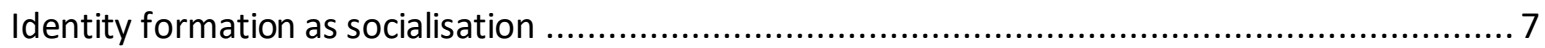

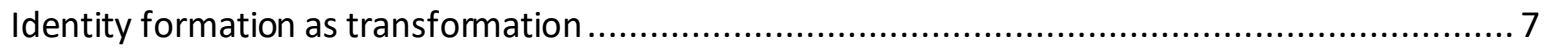

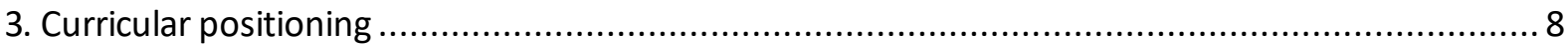

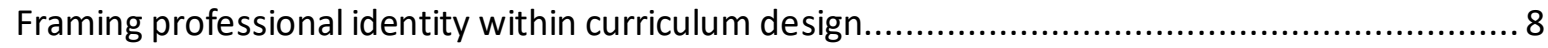

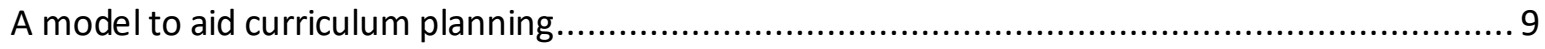

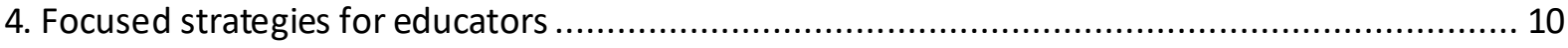

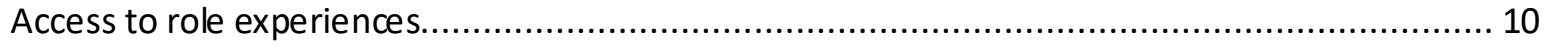

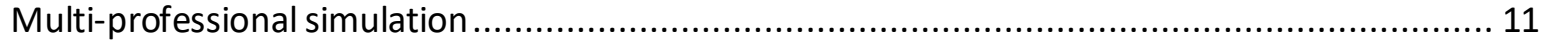

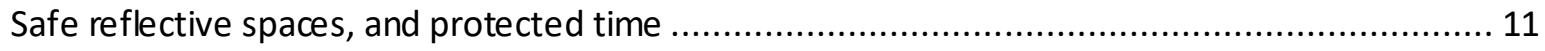

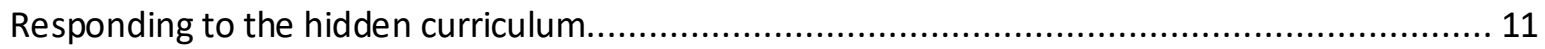

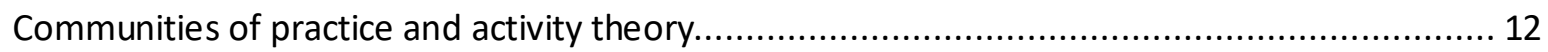

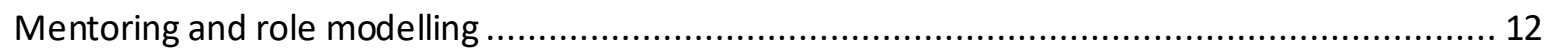

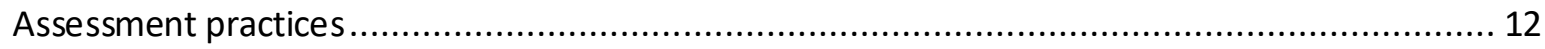

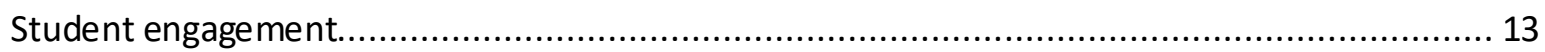

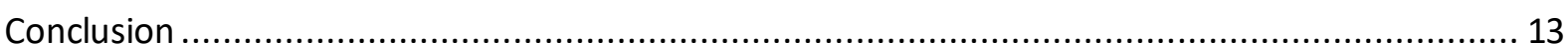

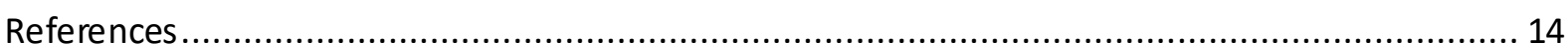




\section{Introduction and overview}

Professional identity formation is a relatively new research area with in health professional education. The overwhelming majority of articles on the topic have appeared since The Carnegie Foundation Report on Medical Education of 2010 (Irby et al., 2010). This report was commissioned for the $100^{\text {th }}$ anniversary of The Flexner Report of 1910 and called for the reform of medical education in the United States and Canada, which it argued had changed little in a century. It explicitly called for professional identity formation to be included in medical curricula. Irby et al defined identity formation as "the development of professional values, actions and aspirations", clarifying the aspirational aspects as "excellence, humanism, accountability and altruism".

The report's curricular recommendations on identity formation were:

- Provide formal ethics instruction, storytelling, and symbols (hono ur codes, pledges, and white coat ceremonies).

- Address the underlying messages expressed in the hidden curriculum and strive to align the espoused and enacted values of the clinical environment.

- Offerfeedback on, reflective opportunities for, and assessment of professionalism in the context of longitudinal mentoring and advising.

- Promote relationships with faculty members who simultaneously support learners and hold them to high standards.

- Create collaborative learning environments committed to excellence and continuous improvement.

In the intervening 20 years since the report's publication, almost 200 articles, reviews and commentaries have appeared within the health professions literature, taking a variety of stances on what is trying to be achieved, and developing perspectives on how it may be realised.

Our aim in writing this chapter was not provide a recipe for how to define, teach or assess professional identity; rather, it was to present a critical discussion, introducing various schools of thought, and to provide theoretically informed suggestions for practice. The chapter explores both conventional identity formation and more complex modern reconfigurations of healthcare professional identity. First, we present an overview of different stances on what professional identity means, drawing on a variety of literature including sociological and organisational scholarship. Second, we explore theories of identity formation including socialisation and transformation. Third, we introduce a model to inform curricular planning, which can be used flexibly within different institutions or contexts. Fourth, we discuss and critique a number of focused strategies for educators including role modelling, mentoring, reflective practice, responding to the hidden curriculum, authentic role experiences and simulation-based education, communities of practice and activity theory, student engagement and assessment practices. Finally, we present our conclusions and possible future directions in healthcare professional identity education.

\section{Conceptions of professional identity}

To understand how professional identities are formed, it is necessary to first to consider what professional identity is. Rather than take a simplistic stance on this, we have drawn on a range of perspectives, which we present under separate sub-headings.

\section{Professional identity as 'ideal': a collective contract with society}

The clinical professions, like legal, religious and other expert professions, are characterised by a lengthy period of study, and a set of standards and skills defined by a governing body that novices must adhere to. The caring professions are also often typified as vocations ('something that you are') rather than occupations ('something that you do'). This intersection between one's identity and the 
defined or presumed attributes, beliefs, values, motives and experiences of one's profession can be said to be one's individual professional identity (Schein, 1978).

Idealised views of how identities are intertwined with behaviour (how what one does is related to who one is) have much sway in the public imagination. These idealised views have important implications for educators and for interprofessional practice generally. The expectations of society on a professional group are often explicitly referred to in the codes of practice of its governing body. For example, the United Kingdom's Royal College of Physicians expects its members to adhere to "a set of values, behaviours, and relationships that underpins the trust the public has in doctors" (Royal College of Physicians, 2005). Similarly, the Nursing \& Midwifery Council promotes its standards as being those "that patients and members of the public tell us they expect from health professionals" (Nursing \& Midwifery Council, 2018). These ideals carry weight not just for the profession and for its' standing in society, but also for healthcare students and trainees, as they orient themselves to what it means to be a healthcare professional. Indeed, these ideal ised values, standards and norms are critical to enabling students and trainees to develop their professional identity: "the 'self' who participates in everyday social interaction can do so only through its recognition of certain cultural norms, values and ideals" (Abbinnett, 2003). These norms, values and ideals publicly legitimise an individual's identity and position in social and organisational terms. They act not only as an explanatory background to our actions and decisions, but also as a definitive frame of reference for actions and decisions that do not accord with relevant standards or prevailing expectations.

\section{Professional identity as 'self and other': tribes and siloes}

A second perspective on professional identity is one that embodies the prevailing views held within their profession, as well as the group's views of other healthcare professionals. Such views may express ideal values and norms, but may also reveal a more functional understanding of what it means to be a healthcare professional. For example, Lingard et al conducted a study asking surgeons and surgical nurses to watch excerpts of tense conversations around the operating table and to discuss what they understood to be the underlying values and motivations behind what was said. Interestingly, participants identified along professional lines, giving their 'side' more complex, noble intentions and the other side shallower stereotypical motivations: the surgeon just wants to make money, while the nurse just wants to finish their shift (Lingard et al., 2002). This finding highlights that identification is a social process. It also suggests that a normative definition of the self may be accompanied by a delegitimation of those who identify with different practices, values and norms. This phenomenon has been referred to as 'professional inclusivity', so that members are expected to socialise with people within the same profession. Its obverse is 'social exclusivity', which is the tendency not to socialise with people from other professions (ledema and Jorm, 2018). Professional inclusivity and exclusivity are terms that capture and highlight the problems linked to identification, such as interprofessional siloes and cross-professional status contests. Such dynamics risk impacting negatively on the high levels of communication and collaboration that are critical to safety in clinical care environments.

\section{Professional identity as an expression of status: hierarchies and power}

A third perspective on identity can be found among sociologists of medicine and of health care. Freidson argued that medical professional identity was as closely tied to status in the labour market as it is to expert skill and ethical values (Freidson, 1970). He saw identity as a complex phenomenon encompassing interests that are economic (income), social (power-control) and expert-professional (skills and knowledge). Zola also regarded professionalisation in healthcare as overlapping with 'medicalisation'. In other words, the processes of enacting medicine and healthcare conspire to convert people's daily existence into a manifestation of either health or illness (Zola, 1972). Zola further described the accrual of status to a profession according to its tende ncy to medicalise pathology. Illich argued that modern medicine, with its customs and rituals, was in effect 
expropriating health as a commodity handed out by doctors, and by turning patients into consumers doctors were actually destroying society's capacity for health (Illich, 1976). Such sociological critiques have contemporary relevance when considering the ongoing privileging of high-end medicine and expensive kinds of clinical care over primary care and community services and the concomitant sociocultural valuation and financial remuneration of those identifying as acute care clinicians (Wass and Gregory, 2017).

\section{Professional identity as a coping strategy: depersonalisation and detachment} The psychoanalyst Menzies-Lyth offers a related perspective (Menzies, 1960). She approached professional identity from the perspective of the work that healthcare professionals were called on to do, and the stresses and conflicts that such work entailed. She construed clinicians' identity as a complex psychological dynamic that enabled them to excuse and cope with the more overwhelming aspects of everyday care work: 'I deal with death, distress and intimate parts of people because I am a nurse'. Menzies-Lyth found clinicians' detachment from the pain of patients was coupled with a denial of their own emotional stress. This, she found, affected not only the clinician-patient relationship, but also the clinician-clinician relationship. She described how the separation between personal and professional identity caused heightened anxiety, particularly for junior clinicians who might have unrealistic expectations placed on them. Identifying as a professional may be accompanied by a feeling that one should possess all the competencies of that professional group. Menzies-Lyth was able to use the detachment created by professional identity to construct an explanatory analysis for a variety of dysfunctional behaviours and coping mechanisms, including the paradox of simultaneously overestimating and undervaluing other clinicians' abilities.

\section{Professional identity as how we are seen by others: culture and identity}

Another strand in professional identity theory relates to culture and identity and ranks self-other relationships as foundational to identity formation and to identity itself. Here, identity formation and identity are not just developmentally conditional on growth of the subject him/herself, but on how the subject is perceived and judged (supportive or otherwise) by others. Identity formation is thus "a process 'located' in the core of the individual and yet also in the core of his [sic] communal culture" (Erikson, 1968 p62). Abbinnett notes that how we view ourselves is influenced by our reaction to how we are treated by others (Abbinnett, 2003). He discusses the stress caused by attempting to contain or deny the impacts of seeing how others view oneself. Popular culture and media can impact on how individuals are treated on account of their profession. For example, stereotypical portrayals within popular media of males within nursing (Weaver et al., 2014), or social workers as under qualified (Gibelman, 2004), are likely to have negative impacts on those identifying within those professions.

\section{Professional identity as contextual and situated: a sociocultural perspective}

Conceptions of professional identity, and what it is to be a healthcare professional, have evolved over time and between different cultures and groups. Learners might also identify differently during different stages of training. For example, an individual may ascribe to different social norms about how one should dress as a medical student, as postgraduate trainee and as a consultant. This leads us to reflect on how conceptions of what it is to be a good healthcare professional are not objective, but a product of the sociocultural conditions in which they are produced. Another example involves the professional identity of pharmacists, which has been affected by the rise of the pharmaceutical industry. Graduating pharmacists may differentially identify as apothecaries, hospital scientists, clinicians responsible for patient outcomes, or as merchants (Kellar, 2019).

Mehta argues that the advent of dissection into Western medical education was facilitated by Cartesian dualism, the separation of mind and body (Mehta, 2011). Foucault also described the medical profession's attitude to the corpse and thus death as medicine's "absolute point of view 
over life" and fundamental to understanding the profession's identity within society (Foucault and Sheridan, $2003 \mathrm{p} 155)$. Through this lens, the role of the healthcare professional is reduced to what they can do for bodies, or parts of bodies, rather than what they can do for the person: the treatment of disease rather than the creation of health, and the 'care/cure dichot omy' (Treiber et al 2015). Since the 1960 s there has been a concerted effort to recreate a more humanistic professional identity within healthcare: re-integrating the mind with the body, the person with the patient, and simultaneously acknowledging the subjectivity and identity of healthcare professionals (Armstrong, 2002).

Current challenges to identity within healthcare professions include the shift from the clinician as an autonomous and sometimes idiosyncratic professional, towards a culture of micro-management, monitoring and incentivisation (ledema, 2006). There are calls to reconcile this battleground in the interests of care quality (Berwick, 2016). We should expect these evolutions in identity to continue as the healthcare context itself evolves.

Professional identity and role fluidity: chimera and chameleon

Professional identity is shifting from clearly delineated role-based structures towards a flexible, multi-stranded and potentially non-coherent behavioural repertoire: a beast composed of many animals (chimera) or that changes its appearance according to context (chameleon). Professional boundaries are being reframed as clinicians are increasingly expected to attend to holistic patient needs, rather than deliver profession-led services. Rising care complexity has meant that clinicians must reconcile themselves with competing demands (multiple patients, co-morbidities, specialty priorities), challenging contexts (resource constraints, management targets, understaffing) and pervasive uncertainties (organisational, scientific, and pragmatic). There is an ever-increasing range of stakeholders involved in patients' care (interpreters, patient liaison officers, quality and safety managers, etc.). This has produced an emphasis on the skills required for relationships and communication across different clinical-technical and socio-cultural domains. Multiple members of the healthcare team are now operating with overlapping roles relating to clinical decision making, prescribing, health promotion and the extent to which they address a patient's psychological or social needs (Nancarrow and Borthwick, 2005).

\section{Professional identity as a transcendent attribute: fact or fiction?}

The final conception of professional identity presently discussed is the tacit assumption that professional identity transcends other forms of identity such as race, religion, class, gender and sexuality. In other words, one's professional attributes are more important than one's personal attributes in both clinician-patient and clinician-clinician interactions. Cohen described this primacy of professional identity as "subordinating all other relevant roles to the professionalidentity. The higher the status of the profession, the more this process of subordinating all other relevant roles will be allowed." (Cohen, 1981) p 177. However, as there are changes in the demographic mix of people entering different professional groups, and yet inertia in professional identity formulations, this suggests that there may be persistent and pervasive influences of variables such class, gender, race or ethnicity on professional identity.

Intersectionality is the notion that we have multiple social identities that are not independent and contribute to how we are perceived, valued and treated by others (Crenshaw, 1991). This supposition has been supported empirically in a study exploring factors influencing professional identity in first year health and social care students. Adams and colleagues concluded that "gender stereotypes, together with masculine/feminine traits and designations, have implications with regard to intergroup relations, and hence to the way in which professional identity is acted out" (Adams et al., 2006 p63). The authors cite related research suggesting that gender is an important determinant of the frequency and nature of interprofessional interactions (Kendrick, 1995) and that 
gender is activated in the course of social perception (Brewer, 1988). Volpe et al found that only 10 of 92 articles included in their review of professional identity formation examined the intersection of personal demographics with professional identity (Volpe et al 2019). This raises the issue of whether our ideas about professional identity formation are socioculturally biased, which disadvantages trainees from non-traditional backgrounds and thus preserves the status quo. Volpe and colleagues' review also reveals how underrepresented minorities report having to repress their personal attributes (gender, race, ethnicity, class, sexuality) in order to succeed and how a lack of role models and social exclusion cause some to self-select out of certain professions. Their review reveals how professional identity as a transcendent attribute, where professionals are valued according to what they do, rather than who they are, is an ideal rather than a reality, and in an era of identity politics and populism, it is perhaps at risk.

\section{Professional identity formation}

Having presented a range of critical perspectives on professional identity, this section moves on to discuss theories on how professional identities are formed.

\section{Identity formation as socialisation}

Goldie describes identity formation as socialisation, whereby students learn to adhere to, internalise or reject prevailing sociocultural norms (Goldie, 2012). In this way, novices rework their identity until it fits into their social surroundings through a process of experimentation and feedback. They ultimately learn to express themselves in a way that is socially acceptable, observing the consequences of their own behaviours. They can also see how they are treated by others because of their professional role, and see the social consequences of others' behaviours, including through vicarious experience, storytelling and cautionary tales. What was initially a behavioural performance eventually becomes habitual as their professional identity becomes an integral part of who they are. This socialisation model accounts for how professional identity can be transmitted forward onto novices. It relies heavily on the existence of positive role models and positive role experiences, as part of the experimentation process is likely to include emulation of aspects of seniors' conduct. The impacts of negative role modelling and suboptimal role experiences can, to a certain extent, be mitigated through the provision of safe reflective spaces, supporting the novice in rejecting rather than adopting those behaviours (Leedham-Green et al., 2019).

\section{Identity formation as transformation}

Jarvis-Selinger et al suggest that mature shifts in identity are a much deeperform of learning than internalising social norms (Jarvis-Selinger et al., 2012). Within health professional education there are transformations that can happen to learners. These might be the by-product of finally grasping a concept where the learner suddenly understands an idea or integrative theory that explains an aspect of their practice, or a transformative experience such as cadaveric dissection or attending their first crash call. Such transformative learning experiences are so called because they fundamentally change the learner cannot be unlearned (Mezirow, 1990). Ultimately, the learner may find himself or herself identifying within a narrow group of peers not necessarily based on professional boundaries, but also boundaries based on experiences, expertise, discourse and interests, as an educator, innovator or researcher.

Perceptual shifts are described by Meyer and Land in their theory of threshold concepts (Meyer and Land, 2005). True perceptual shifts do not occur very often, and can be profoundly unsettling, opening up new affective and cognitive domains. Perkins introduced the concept of 'troublesome knowledge' as a precursor to transformation (Perkins, 1999). It is called troublesome because it does not fit into the learner's current conceptual understanding. For example, a medical student may fixate on their role as physician-as-healer and find the patient with chronic symptoms or a dying 
patient outside their perceptual understanding of their role and therefore troublesome. Nursing students might see the provision traditionally physician-led therapies as outside their professional role, requiring a perceptual shift in what it means to be a nurse before truly engaging in this learning (Hurley, 2013). To progress from one identity to another involves transitioning though an inbetween space or the liminal state (Turner, 1987). This is a transitional place, in which students see the need to let go of an earlier identity, but still have not quite grasped and integrated the new identity. The role of the educator is then to guide students safely across boundaries into a new space. These shifts in identity are likely to be greatest at transitional moments, such as from school to higher education (Nyström, 2009), as well as from higher education to the clinical workplace, from trainee to professional, or from professional to retiree. A true shift in perspective often involves new ways of talking, so that the 'cadaver' becomes the 'donor's body'. You can be socialised into using this language, but ultimately it entails a shift in perception.

Atherton describes how learners might resist identity transformation, as this type of learning involves loss: there is destabilisation as the old self is lost, disorientation whilst in a liminal state, and the hard work of re-orientation as a new self is constructed (Atherton, 1999). Land et al argue that the liminal state is an uncomfortable and vulnerable one and that students are unlikely to progress independently across these thresholds without expert support, as the knowledge they need to progress might be outside their previous understanding of their world. They argue for educators to promote a 'positive psychology' of hope, self-efficacy and coherence to support learners through the emotional cost of transformation (Land et al., 2016).

\section{Curricular positioning}

Whether one sees professional identity formation as a process of socialisation or transformation, or as a combination of both, there are considerations for curricular planning and positioning which we now present.

\section{Framing professional identity within curriculum design}

The multiplicity of perspectives on professional identity raises important questions on how to frame professional identity formation within curricular design. There are likely to be multiple perspectives on what professional identity is and how it is formed, and educators will need to be both critical and creative about how institutions set about profession alising healthcare students.

Education on professional identity that simply reiterates the formally articulated codes of conduct of a profession, is likely to yield curricula that induct students into idealised forms of professional identity. As such, the teaching will not give emphasis to the more pragmatic and even dysfunctional aspects of their profession. Therefore, teaching may risk alienating students if they are unable to reconcile the espoused ideal with what they see practised, if they are unable to criticise what they perceive to be adverse influences, or if they are unable to reconcile their personal identity within the prevailing sociocultural norms of their profession. Trying to mould students towards an institutionally predefined concept of professional id entity may also be problematic for numerous other reasons. For example, alienating students if educators appear to be prejudging their sense of self and their motivations, or to be imposing reductive judgements about who students will become, what they should do and why.

Teaching that emphasises professional identity as an expression of so ciological status, the medicalisation of everyday life, or as a way of coping with unpleasant tasks may also be limited. Such an approach may not give due attention to the high standards, altruistic aims and demanding practices defining the profession. It risks glossing over professionals' vocational calling, and their commitment to self-sacrifice and others' well-being. Emphasising the complexity and instability of contemporary healthcare practice may highlight the increasing number of competencies and selves 
required for being a good clinician. However, as the boundaries of professional roles stretch and blur, this may risk the formation of a professional identity.

Looking at students' perspectives on being professionalised, Birden \& Usherwood found that medical students arrived with pre-formed conceptions of professionalism and professional identity and resented being taught to become professional (Birden \& Usherwood 2013). Their qualitative study across three medical schools identified the following themes. First, students seemed confident in their developing professional identities and held a pragmatic conceptual framework (definition) of professionalism based on their experience and reflection. Second, students had a low regard for the professionalism teaching they had experienced and for the ways in which professionalism had been assessed in their learning programs. Third, students had learned to "game the system", giving assessors the results on reflective writing assignments that they believed their assessors wanted to hear, and that would gain them a pass. Fourth, students saw the situations they experienced in clinical placements as being far more complex than the ones they were presented with in teaching sessions, which they considered superficial or trivial. Fifth, students considered experiential learning - observing good professional practice - to be the best way (some viewed as the only way) to learn professionalism. And finally, students consolidated what they learned, and formed their individual mental model of professionalism, through discussion and reflection with their peers in medical school. These findings suggest that learning happens through authentic role experiences and reflective discussion rather than in the classroom. This has implications for differential attainment based on inclusivity, and reaffirms that attempts to teach and assess professionalism and professional identity directly are complex and may even be counterproductive.

To avoid caricaturising and devaluing professional identity formation, curriculum designers might instead consider fostering criticality and an appreciation of complexity in their students. Approaches might include fostering the articulation of multiple perspectives through humanities-based approaches to clinical education (Zahra and Dunton, 2017); fostering student engagement in curriculum design and delivery (Mann, 2001); acknowledging and addressing challenges to inclusivity (Aysola et al., 2018); and using students' lived experiences of the clinical workplace as foci for reflective deliberations and debrief (Leedham-Green et al., 2019).

\section{A model to aid curriculum planning}

Identity as an educational goal is problematic for a variety of reasons, some of which are discussed above. Although problematic, it does not mean that identity is not an important educational goal. Students may take time to internalise and enact the espoused values and behaviours of their chosen profession, and may need support to develop an aspirational professional identity that feels congruent for them. Identity formation therefore requires educators to think about the topic in a different way to traditional competency-based education.

Depending on one's stance on professional identity formation, the role of the educator may not be to teach people what or how to be, rather it may be to support the development and enactment of a positive identity. This requires curriculum planners to attend to the behavioural and contextual drivers of identity formation.

As with any complex intervention, there is unlikely to be a single solution and curricular activities are more likely to be successful if they target multiple drivers across multiple domains (Pai et al., 2018). Behavioural change theory, rooted in health psychology, tells us to attend to participants' capabilities, opportunities and motivations (Michie and Johnston, 2012). A complementary model, Bronfenbrenner's ecological model (Bronfenbrenner, 1994) describes how interventions can be targeted at different interconnected levels: personal, interpersonal, teams, organisation, and society more widely. 
By combining the two models, it is possible to create a grid comprised of discrete cells, within which educators can list a range of actions designed to support professional identity formation across multiple domains (Figure 1). The grid's contents, completed here for illustrative purposes, will need to be considered locally, taking into consideration local resources, team dynamics and organisational priorities. The grid's purpose is to stimulate curricular planning that considers a broad range of potential interventions.

Figure 1: An example of a curricular planning grid across behavioural and contextual domains

\begin{tabular}{|c|c|c|c|c|c|}
\hline & Personal & Interpersonal & Team & Organisational & Societal \\
\hline Capability & $\begin{array}{l}\text { Knowledge of team } \\
\text { roles and } \\
\text { expectations } \\
\text { Recruitment based } \\
\text { on orientation to } \\
\text { role }\end{array}$ & $\begin{array}{l}\text { Collaborative skills } \\
\text { and proficiencies } \\
\text { Interpersonal } \\
\text { respect and } \\
\text { inclusivity }\end{array}$ & $\begin{array}{l}\text { Address inter- } \\
\text { professional power } \\
\text { imbalances } \\
\text { Interprofessional } \\
\text { respect and } \\
\text { inclusivity }\end{array}$ & $\begin{array}{l}\text { Address the hidden } \\
\text { curriculum } \\
\text { Unconscious bias } \\
\text { training } \\
\text { Protected time for } \\
\text { clinical teaching }\end{array}$ & $\begin{array}{l}\text { Acknowledge and } \\
\text { respond to societal } \\
\text { influences, for } \\
\text { example } \\
\text { marketization of } \\
\text { healthcare }\end{array}$ \\
\hline Opportunity & $\begin{array}{l}\text { Access to authentic } \\
\text { role experiences }\end{array}$ & $\begin{array}{l}\text { Mentoring } \\
\text { Personalised support } \\
\text { through transitions }\end{array}$ & $\begin{array}{l}\text { Legitimate junior } \\
\text { team roles } \\
\text { Safe reflective } \\
\text { spaces } \\
\text { Multi-professional } \\
\text { simulation }\end{array}$ & $\begin{array}{l}\text { Students as co- } \\
\text { creators of curricular } \\
\text { content } \\
\text { Longitudinal } \\
\text { placements and } \\
\text { apprenticeship } \\
\text { learning }\end{array}$ & $\begin{array}{l}\text { Opportunities for } \\
\text { learner engagement } \\
\text { within wider society, } \\
\text { for example } \\
\text { volunteering }\end{array}$ \\
\hline Motivation & $\begin{array}{l}\text { Encouragement, } \\
\text { rewards, sanctions } \\
\text { Imagining self within } \\
\text { role } \\
\text { Building confidence } \\
\text { and self-efficacy }\end{array}$ & $\begin{array}{l}\text { Visible role models } \\
\text { Coaching } \\
\text { approaches to } \\
\text { supervision and } \\
\text { remediation }\end{array}$ & $\begin{array}{l}\text { Team feedback } \\
\text { Team building }\end{array}$ & $\begin{array}{l}\text { Assessment culture } \\
\text { that supports } \\
\text { complexity and } \\
\text { uncertainty } \\
\text { Personal choice in } \\
\text { professional } \\
\text { developmental } \\
\text { activities }\end{array}$ & $\begin{array}{l}\text { Recognise and } \\
\text { reward wider } \\
\text { societal engagement }\end{array}$ \\
\hline
\end{tabular}

\section{Focused strategies for educators}

This section outlines in greater detail some of the strategies listed in Figure 1 to promote professional identity formation in health professional education.

\section{Access to role experiences}

Access to role experiences and role models is an essential component of professional identity formation (Cruess et al., 2008). The contours of professional identity can never be exhaustively delineated through formal or even informal instruction. Exactly what the role model articulates about the profession may not be the principle influence, as much as the student's observations of their seniors in role. Becoming a healthcare professional thus requires participation in the profession's in situ practices in order to appreciate and act on their complexities, and to understand the evolving character of the contemporary clinician's identity. Role experiences are contingent on novices being granted access to that practice by those who determine and maintain its boundaries and entry points. This might be a practical boundary, such as passing an exam, or a social entry point such as inclusion into a reflective discussion after a difficult operation. The privileging of inclusion to certain demographics can be informed by the literature on retention and success in higher education (Thomas et al., 2017). 


\section{Multi-professional simulation}

Given the complexities of clinical care, it is not surprising that the deployment of experiential learning opportunities including simulation-based education is gathering pace. There are however gaps between simulation and actual clinical-professional practice, and between formal debrief and informal workplace learning. Simulation-based education inevitably loses some of the full complexity of clinical settings, and participants' simulated conducts are unlikely to project the full range of conducts and responses elicited in real-time amidst emergent care circumstances. Nonetheless, it has the potential to open up opportunities for transferrable learning about professional identity including perpetual shifts relating to hierarchy, leadership and distributed expertise. Simulationbased education as an opportunity for identity formation may not be effective if it is limited to the reproduction of ideal-type conducts and identities. It loses validity if it becomes a self-referential condition that no longer bridges to the real world (Bligh and Bleakley, 2006). For simulation to be meaningful, fidelity becomes less about the physical replication of reality, and more about the functional representation of real-world cues and stimuli (Hamstra et al., 2014).

\section{Safe reflective spaces, and protected time}

The quality of debrief following simulation-based education is seldom replicated in the rushed but potentially valuable conversations that happen in real-time in the clinical workplace. Students entering the workplace for the first time will have fresh eyes on the idiosyncrasies and peculiarities of workplace practice. Learners may have questions about real-time practices encountered on placements that carry great significance for them, including questioning the moral-ethical dimensions of care. Students may not feel safe questioning their seniors in the workplace, and therefore would benefit from the creation of safe reflective spaces. For example, a student might ask how a patient can be expected to assume responsibility for negotiating their subsequent referrals and shared decision making, after having been informed they have metastatic cancer and is clearly consumed by emotion. These kinds of questions make it possible for the learner to negotiate and navigate, the emotional and moral dimensions of care in addition to the clinical-technical dimensions of care. These impact on their ability to invest themselves fully in the priorities and prerogatives of the clinical workplace and ultimately to align their personal identity with that of their profession. Protected time to support students in processing troublesome knowledge is needed. The creation of safe reflective spaces that are share $d$ by both faculty and students is a challenge. The evidence emerging on student involvement in Schwartz Rounds is promising (Zervos and Gishen, 2019), as is research on strategies for facilitating authentic reflective practice (Wald, 2015).

\section{Responding to the hidden curriculum}

Hidden curriculum is a term used to describe the learning that happens outside planned educational activities (Hafferty and O'Donnell, 2015). For example, learning through observing interprofessional behaviours in the workplace, or absorbing tacit rules and conventions. Hidden curricula are inevitable, and can have both positive and negative impacts on student learning, and therefore warrant careful examination. In order to study the hidden curriculum in relation to professional identity formation, educators need to develop strategies to explore the clinical learning environment through the eyes of their students (Leedham-Green et al., 2019). The hidden curriculum can never be eliminated, but Haidet \& Teal suggest that interventions should instead be directed upstream towards the forces fostering the hidden curriculum and downstream towards mitigating its impacts (Haidet and Teal, 2015). Examples relating to professional identity formation might include support for better role modelling through protected time for clinical teaching, or through the provision of safe, reflective spaces to mitigate sub-optimal experiences. 


\section{Communities of practice and activity theory}

Creuss et al suggest that attending to the determinants of identity formation at a team level can be informed by the literature on communities of practice (Cruess et al., 2019). Wenger describes how learning is socially constructed, shifting the analytic focus from the individual as learner, to learning as participation in a social world. Wenger critiques the theoretic inadequacy of blaming the marginalised for being marginal. He describes how identity is formed through access to competence and experience, and 'mutual engagement around a joint enterprise', and gradual movement from the periphery to the centre of a community of practice (Wenger, $1998 \mathrm{p214})$. This is challenging in an undergraduate context unless there are stable teams that students can be invited to join, longitudinal placements for students within those teams, and opportunities for students to engage in legitimate team roles.

Research on longitudinal integrated clerkships is likely to be helpful, whereby students undertake their core clinical learning within a single team rather than rotating through specialties, with responsibility for patients rather than tasks (Hirsh et al., 2012). Bates et al found explicit links between competency and identity in a longitudinal integrated clerkship (Bates et al., 2013). Longitudinal relationships between preceptors and students also allow team members to make informed entrustment decisions (Hirsh et al., 2014). This means that participation can be pitched at a level that stretches the student without compromising their ability to complete a task safely with support at hand, at the zone of proximal development (Vygotsky et al., 1978). Where there is no 'team' and activities are organised around fluid combinations or 'knots' of professionals that form and reform depending on the task, this becomes doubly complicated. Bleakley suggests that student identity formation in this context needs to be informed by activity theory (Engeström, 1999) where students learn through engagement in multi-professional activities (Bleakley, 2011). For example, an operation, rather than engagement in a surgical 'firm'. This requires clarity of handover regarding entrustment decisions as teams dissolve and reform.

\section{Mentoring and role modelling}

On an interpersonal level, interventions to support professional identity formation include mentoring and role modelling. If these are left to grow organically there is a risk that they favour hegemony over diversity. Edmunds et al, in their systematic review of gender in clinical academia, found informal networks tend to favour those with highest social capital, while learners with low social capital tend not to ask powerful incumbent mentors to support them (Edmunds et al., 2016). Furthermore, a lack of diverse role models can result in disidentification, compensatory behaviours and stereotype threat. The literature on retention and success within higher education has recommendations for how mentoring and role modelling can be facilitated to promote inclusivity and more equitable educational attainment (Thomas et al., 2017). Unconscious bias training is another potentially fruitful area for action (Sukhera and Watling, 2018).

\section{Assessment practices}

Identity itself is a social construct and attempts to measure it as an attribute through validated scales will only be as valid as the constructs the scale is based on. This is further complicated by the fact that as soon as any scale becomes a target, either for faculty or students, it is unlikely to remain a valid test of the underlying quality it was designed to measure.

Any test based on observation is fundamentally a test of behaviour rather than identity. Behaviours therefore are an indirect measure of professional identity and require interpretation. If a student fails to enact professional ideals in a given situation there may be many explanations, such as a failure of understanding or skills, or an indication of a wider cultural, educational or contextual problem, and not necessarily a failure of identity formation. 
Rather than trying to measure professional identity formation, we suggest that assessment practices focus on providing opportunities and motivation for engagement in complex learning and engagement in the workplace. For example, an assessment that requires learners to reflect on team dynamics and implications for patient safety in the operating theatre.

The creation of larger healthcare schools has led, particularly in medicine, to an assessment culture dominated by machine-marked written examinations and structured tests of isolated clinical skills. The prevailing assessment paradigm within medical education has become one of performative measurement to pre-defined standards, which favours rote learning over the development of cognitive maturity or criticality. There is a risk that these students retreat from learning in the workplace if examinations favour memorisation of clinical guidelines and textbook performances of individual rather than team skills.

This entrenched assessment paradigm disadvantages teaching and learning in the humanities and the behavioural and social sciences (Litva and Peters, 2008). In an over-crowded curriculum, many students will necessarily prioritise activities that allow them to progress over more optional complex learning activities (Cilliers et al., 2012). There is a call to reduce the burden of assessment, whilst simultaneously increasing the complexity of assessment modalities to support assessment in authentic contexts where standardisation is impossible (van der Vleuten et al., 2017). There is a need to acknowledge that in many contexts reductionism in the pursuit of objectivity risks losing validity.

There is an emerging literature on integrative assessments (Crisp, 2012), programmatic assessment (Schuwirth and Vleuten, 2019), as well as the maturing literature on how portfolios can be redesigned to support authentic, complex learning (Driessen, 2017). Educators may find these more appropriate assessment modalities to promote the behaviours and workplace-based activities that drive positive professional identity formation.

\section{Student engagement}

Engaging students as partners in educational design is a growing movement (Peters et al., 2019). There are likely to be multiple benefits in students co-designing their own professionalisation curricula, potentially in collaboration with patients or other interprofessional students. Students are likely to view their curriculum through a forward-looking rather than retrospective lens, as well as attending to the perceived value and authenticity of assessments. Co-design can work on an individual as well as curricular level. Goldie describes a post-modernist stance on professional identity formation, where the educator's role is to support graduates in constructing their own professional identity, developing attributes that feel authentic them (Goldie 2012). This stance might involve co-designing opportunities for learning that strengthen their sense of personal identity within their work context. For example, through research activities or projects that feel congruent to their intrinsic values and motivations.

\section{Conclusion}

Educating healthcare professionals in ways that enable them to retain and enact aspirational professional identities within the demands of contemporary healthcare remains a complex issue. This chapter has examined professional identity as ideal, as well as the more pragmatic identities as enacted within the challenges of a modern healthcare context. We have touched on critical aspects relating to hierarchies and inclusion, and the future of professional identity as role boundaries blur in response to rising care complexity and holistic rather than siloed approaches to patient care. In addition to providing a range of perspectives on healthcare identity, and the dynamics of its formation, this chapter has set out a range of parameters and enabling strategies to sup port identity formation within health professional curricula whilst acknowledging the challenges that these 
phenomena pose for novices, including the hidden curriculum. We have called for educators to enact the epistemologies of the behavioural and social sciences as well as the humanities in designing their professionalisation curricula, rather than the prevailing paradigm that is more suited to the biomedical sciences, particularly in relation to educational goals and assessment. Finally, we have provided a flexible framework for educators that target multiple behavioural and contextual domains, so that strategies to enable the formation and enactment of a personally congruent professional identity can be considered within a variety of healthcare professio nal contexts. There will always be developments and challenges for how novices professionalise and for how educators educate. Looking forward into a challenging and uncertain future for health and healthcare, supporting students in developing a positive identity and outlook, through expertise, criticality and cognitive maturity is an important strategy with the potential for enduring positive impacts.

\section{References}

ABBINNETT, R. 2003. Culture and Identity: Critical Theories, London, Sage Publications Limited. ADAMS, K., HEAN, S., STURGIS, P. \& CLARK, J. M. 2006. Investigating the factors influencing professional identity of first-year health and social care students. Learning in Health and Social Care, 5, 55-68.

ARMSTRONG, D. 2002. A New History of Identity, Palgrave Macmillan UK.

ATHERTON, J. 1999. Resistance to learning: a discussion based on participants in in-service professional training programmes. Journal of Vocational Education \& Training, 51, 77-90.

AYSOLA, J., BARG, F. K., MARTINEZ, A. B., KEARNEY, M., AGESA, K., CARMONA, C. \& HIGGINBOTHAM, E. 2018. Perceptions of Factors Associated With Inclusive Work and Learning Environments in Health Care Organizations A Qualitative Narrative Analysis. Jama Network Open, 1.

BATES, J., KONKIN, J., SUDDARDS, C., DOBSON, S. \& PRATT, D. 2013. Student perceptions of assessment and feedback in longitudinal integrated clerkships. Medical Education, 47, 362374.

BERWICK, D. M. 2016. Era 3 for Medicine and Health Care. Jama, 315, 1329-30.

BLEAKLEY, A. 2011. Learning and Identity Construction in the Professional World of the Surgeon. In: FRY, H. \& KNEEBONE, R. (eds.) Surgical Education: Theorising an Emerging Domain. Dordrecht: Springer Netherlands.

BLIGH, J. \& BLEAKLEY, A. 2006. Distributing menus to hungry learners: can learning by simulation become simulation of learning? Medical Teacher, 28, 606-613.

BREWER, M. B. 1988. A dual process model of impression formation. A dual process model of impression formation. Hillsdale, NJ, US: Lawrence Erlbaum Associates, Inc.

BRONFENBRENNER, U. 1994. Ecological models of human development. Readings on the development of children, 2, 37-43.

CILLIERS, F. J., SCHUWIRTH, L. W., HERMAN, N., ADENDORFF, H. J. \& VAN DER VLEUTEN, C. P. 2012. A model of the pre-assessment learning effects of summative assessment in medical education. Adv Health Sci Educ Theory Pract, 17, 39-53.

COHEN, H. A. 1981. The Nurse's Questfor a Professional Identity, Addison-Wesley Publishing Company, Medical/Nursing Division.

CRENSHAW, K. 1991. Mapping the Margins: Intersectionality, Identity Politics, and Violence against Women of Color. Stanford Law Review, 43, 1241-1299.

CRISP, G.T. 2012. Integrative assessment: reframing assessment practice for current and future learning. Assessment \& Evaluation in Higher Education, 37, 33-43.

CRUESS, S. R., CRUESS, R. L. \& STEINERT, Y. 2008. Role modelling-making the most of a powerful teaching strategy. BMJ, 336, 718-721.

CRUESS, S. R., CRUESS, R. L. \& STEINERT, Y. 2019. Supporting the development of a professional identity: General principles. Medical Teacher, 41, 641-649.

DRIESSEN, E. 2017. Do portfolios have a future? Advances in Health Sciences Education, 22, 221-228. 
EDMUNDS, L. D., OVSEIKO, P. V., SHEPPERD, S., GREENHALGH, T., FRITH, P., ROBERTS, N. W., POLOLI, L. H. \& BUCHAN, A. M. 2016. Why do women choose or reject careers in academic medicine? A narrative review of empirical evidence. The Lancet, 388, 2948-2958.

ENGESTRÖM, Y. 1999. Activity theory and individual and social transformation. Perspectives on activity theory, 19.

ERIKSON, E. H. 1968. Identity: youth and crisis, Oxford, England, Norton \& Co.

FOUCAULT, M. \& SHERIDAN, A. 2003. The Birth of the Clinic: An Archaeology of Medical Perception, Routledge.

FREIDSON, E. 1970. Profession of medicine: a study of the sociology of applied knowledge, Dodd, Mead.

GIBELMAN, M. 2004. Television and the Public Image of Social Workers: Portrayal or Betrayal? Social Work, 49, 331-334.

GOLDIE, J. 2012. The formation of professional identity in medical students: Considerations for educators. Medical Teacher, 34, E641-E648.

HAFFERTY, F. W. \& O'DONNELL, J. F. 2015. The hidden curriculum in health professionaleducation, Dartmouth College Press.

HAIDET, P. \& TEAL, C. R. 2015. Organizing chaos: A conceptual framework for assessing hidden curricula in medical education. The hidden curriculum in health professionaleducation. Dartmouth College Press.

HAMSTRA, S. J., BRYDGES, R., HATALA, R., ZENDEJAS, B. \& COOK, D. A. 2014. Reconsidering Fidelity in Simulation-Based Training. Academic Medicine, 89, 387-392.

HIRSH, D., WALTERS, L. \& PONCELET, A. N. 2012. Better learning, better doctors, better delivery system: possibilities from a case study of longitudinal integrated clerkships. Med Teach, 34, 548-54.

HIRSH, D. A., HOLMBOE, E. S. \& TEN CATE, O. 2014. Time to trust: longitudinal integrated clerkships and entrustable professional activities. Academic Medicine, 89, 201-204.

HURLEY, J. 2013. Perceptual shifts of priority: a qualitative study bringing emotional intelligence to the foreground for nurses in talk-based therapy roles. Journal of Psychiatric and Mental Health Nursing, 20, 97-104.

IEDEMA, R. 2006. (Post-) bureaucratizing medicine: Health reform and the reconfiguration of contemporary clinical work. Gotti, M./Salanger-Meyer, F.(Hg.): Advances in Medical Discourse Analysis: Oral and Written Contexts. Bern: Peter Lang, 111-131.

IEDEMA, R. \& JORM, C. 2018. Nurturing anaesthetic expertise: On narrative, affect and professional inclusivity. Communication \& Medicine, 15, 53-64.

ILLICH, I. 1976. Limits to Medicine Medical Nemesis: The Exploration of Health.

IRBY, D. M., COOKE, M. \& O'BRIEN, B. C. 2010. Calls for Reform of Medical Education by the Carnegie Foundation for the Advancement of Teaching: 1910 and 2010. Academic Medicine, 85, 220227.

JARVIS-SELINGER, S., PRATT, D. D. \& REGEHR, G. 2012. Competency Is Not Enough: Integrating Identity Formation Into the Medical Education Discourse. Academic Medicine, 87, 11851190.

KELLAR, J. 2019. Who Are We?-The Evolving Professional Role and Identity of Pharmacists in the 21st Century. In: BABAR, Z.-U.-D. (ed.) Encyclopedia of Pharmacy Practice and Clinical Pharmacy. Oxford: Elsevier.

KENDRICK, K. 1995. Nurses and doctors: a problem of partnership. In:SOOTHILL, K., MACKAY, L. \& WEBB, C. (eds.) Interprofessional relations in health care. London: E. Arnold.

LAND, R., MEYER, J. H. \& FLANAGAN, M. T. 2016. Threshold concepts in practice, Springer.

LEEDHAM-GREEN, K. E., KNIGHT, A. \& IEDEMA, R. 2019. Intra- and interprofessional practices through fresh eyes: a qualitative analysis of medical students' early workplace experiences. BMC Med Educ, 19, 287.

LINGARD, L., REZNICK, R., DEVITO, I. \& ESPIN, S. 2002. Forming professional identities on the health care team: discursive constructions of the 'other' in the operating room. Medical Education, $36,728-734$. 
LITVA, A. \& PETERS, S. 2008. Exploring barriers to teaching behavioural and social sciences in medical education. Med Educ, 42, 309-14.

MANN, S. J. 2001. Alternative Perspectives on the Student Experience: Alienation and engagement. Studies in Higher Education, 26, 7-19.

MEHTA, N. 2011. Mind-body dualism: A critique from a health perspective. Mens sana monographs, 9, 202.

MENZIES, I. E. P. 1960. A Case-Study in the Functioning of Social Systems as a Defence against Anxiety:A Report on a Study of the Nursing Service of a General Hospital. Human Relations, 13, 95-121.

MEYER, J. H. F. \& LAND, R. 2005. Threshold concepts and troublesome knowledge (2): Epistemological considerations and a conceptual framework for teaching and learning. Higher Education, 49, 373-388.

MEZIROW, J. 1990. How critical reflection triggers transformative learning. Fostering critical reflection in adulthood, 1, 20.

MICHIE, S. \& JOHNSTON, M. 2012. Theories and techniques of behaviour change: Developing a cumulative science of behaviour change. Health Psychology Review, 6, 1-6.

NANCARROW, S. A. \& BORTHWICK, A. M. 2005. Dynamic professional boundaries in the healthcare workforce. Sociology of Health \& Illness, 27, 897-919.

NURSING \& MIDWIFERY COUNCIL2018. The code: Professional standards of practice and behaviour for nurses, midwives and nursing associates. . London: Nursing \& Midwifery Council,.

NYSTRÖM, S. 2009. The dynamics of professional identity formation: Graduates' transitions from higher education to working life. Vocations and learning, 2, 1-18.

PAI, M., SCHUMACHER, S. G. \& ABIMBOLA, S. 2018. Surrogate endpoints in global health research: still searching for killer apps and silver bullets? BMJ Global Health, 3, e000755.

PERKINS, D. 1999. The many faces of constructivism. Educationalleadership, 57, 6-11.

PETERS, H., ZDRAVKOVIC, M., JOÃO COSTA, M., CELENZA, A., GHIAS, K., KLAMEN, D., MOSSOP, L., RIEDER, M., DEVI NADARAJAH, V. \& WANGSATURAKA, D. 2019. Twelve tips for enhancing student engagement. Medical teacher, 41, 632-637.

ROYAL COLLEGE OF PHYSICIANS 2005. Doctors in society: medical professionalism in a changing world.

SCHEIN, E. H. 1978. Career dynamics: Matching individualand organizational needs, Addison Wesley Publishing Company.

SCHUWIRTH, L. W. T. \& VLEUTEN, C. P. M. V. D. 2019. Current Assessment in Medical Education: ProgrammaticAssessment.

SUKHERA, J. \& WATLING, C. 2018. A Framework for Integrating Implicit Bias Recognition Into Health Professions Education. Academic Medicine, 93, 35-40.

THOMAS, L., HILL, M., O'MAHONY, J. \& YORKE, M. 2017. Supporting student success: strategies for institutional change. What Works.

TURNER, V. 1987. Betwixt and between: The liminal period in rites of passage. Betwixt and between: Patterns of masculine and feminine initiation, 3-19.

VAN DER VLEUTEN, C., SLUIJSMANS, D. \& JOOSTEN-TEN BRINKE, D. 2017. Competence assessment as learner support in education. Competence-basedvocational and professionaleducation. Springer.

VYGOTSKY, L. S., COLE, M., JOHN-STEINER, V., SCRIBNER, S. \& SOUBERMAN, E. 1978. Mind in Society: Development of Higher Psychological Processes, Harvard University Press.

WALD, H. S. 2015. Professional Identity (Trans)Formation in Medical Education: Reflection, Relationship, Resilience. Academic Medicine, 90, 701-706.

WASS, V. \& GREGORY, S. 2017. Not 'just' a GP: a call for action. British Journal of General Practice, 67, 148-149.

WEAVER, R., FERGUSON, C., WILBOURN, M. \& SALAMONSON, Y. 2014. Men in nursing on television: exposing and reinforcing stereotypes. Journal of Advanced Nursing, 70, 833-842.

WENGER, E. 1998. Communities of practice: Learning, meaning, and identity, Cambridge university press. 
ZAHRA, F. S. \& DUNTON, K. 2017. Learning to look from different perspectives - what can dental undergraduates learn from an arts and humanities-based teaching approach? BrDent J, 222, 147-150.

ZERVOS, M. \& GISHEN, F. 2019. Reflecting on a career not yet lived: student Schwartz Rounds. Clin Teach, 16, 409-411.

ZOLA, I. K. 1972. Medicine as an Insitution of Social Control. The Sociological Review, 20, 487-504. 